\title{
TCC's
}

\section{PROJETO E SIMULAÇÃO DE MULETA DE BAMBU TIPO ASA}

\section{GABRIEL OSTAPIV | UTFPR-PB \\ FABIANO OSTAPIV, Dr. |UTFPR-PB}

\section{INTRODUÇÃO}

Muletas são equipamentos essenciais para o auxílio de pessoas que possuem algum tipo de limitação temporária ou permanente na locomoção. Diniz (2017), diz que o uso frequente pode causar diversos tipos de lesões, principalmente nas axilas e nos pulsos dos usuários, devido à pressão causada pela reação dos apoios sobre estas partes do corpo humano.

Este trabalho tem como objetivo principal construir e testar protótipos de uma muleta de bambu, com formato inovador, chamada de muleta tipo asa. Espera-se que o uso deste tipo de muleta permita diminuir o índice de lesões por uso frequente, bem como ampliar as possibilidades de uso do equipamento como elemento fisioterapêutico. Ainda neste trabalho foram desenvolvidas análises computacionais numéricas sobre um modelo virtual da nova muleta de bambu, buscando avaliar as deflexões sobre o equipamento, causados por esforços mecânicos de carregamento vertical.

Pedaços de colmos de bambu da espécie Phyllostachys aurea, também conhecida como cana-da-índia, provenientes de varas de pesca vendidas comercialmente, foram utilizados como material estrutural no protótipo. O objetivo do uso de varas de pesca é permitir a fácil reprodução bem como a redução do custo produtivo, com o intuito de tornar este tipo de muleta acessível à população de baixa renda.

A simulação numérica computacional foi realizada com o software ANSYS Workbench, usado para análises estruturais de geometrias complexas, e para a criação e melhoria de protótipos, como realizado no trabalho de Ostapiv et al, (2019).

Como resultado a muleta fabricada, simulada e testada mostrou-se mecanicamente resistente, de fácil construção, baixo custo e funcionalmente eficiente, agregando novas funções em relação ao equipamento tradicional.

Conforme resultados da simulação numérica, mostrados nas Figuras 1 e 2, ocorre um deslocamento máximo na parte superior da muleta, de cerca de $1 \mathrm{~mm}$ para baixo, e uma deflexão máxima de 3,9 mm na direção horizontal, tendendo a abrir o arco superior da muleta, quando utilizado por uma pessoa de $80 \mathrm{Kg}$.

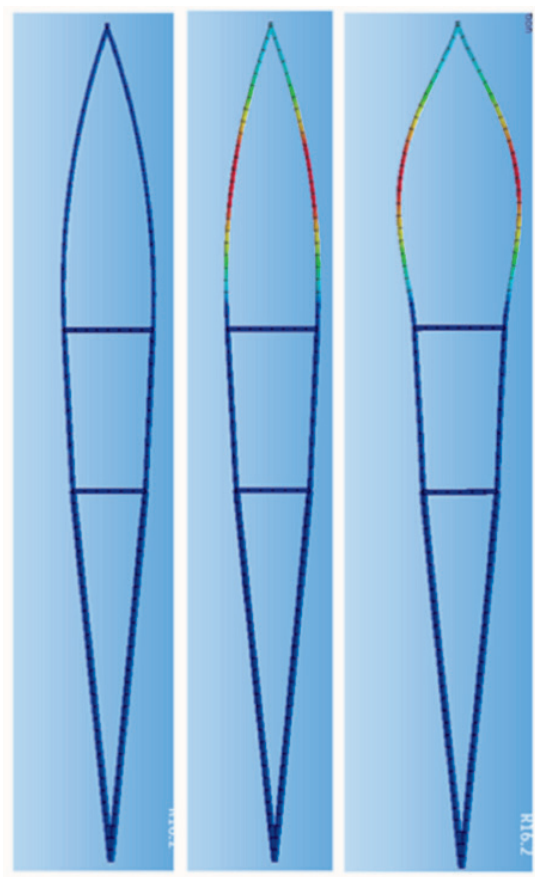

Figura 1 - Simulação do modelo computacional. Fonte: Autor 2020

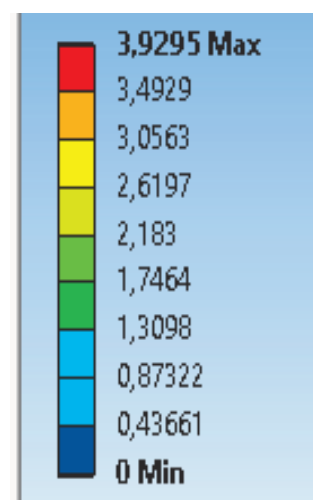

Figura 2 - Escala de cores, deflexão (mm). Fonte: Autor 2020 
Os testes de campo mostraram que: a muleta cumpriu o objetivo de diminuir a pressão e o desconforto nas axilas do usuário, devido ao uso dos tirantes elásticos e cintas acolchoadas com velcro; e se mostrou funcional, suportando tranquilamente o peso de uma pessoa de $80 \mathrm{~kg}$, como mostrado na Figura 3.
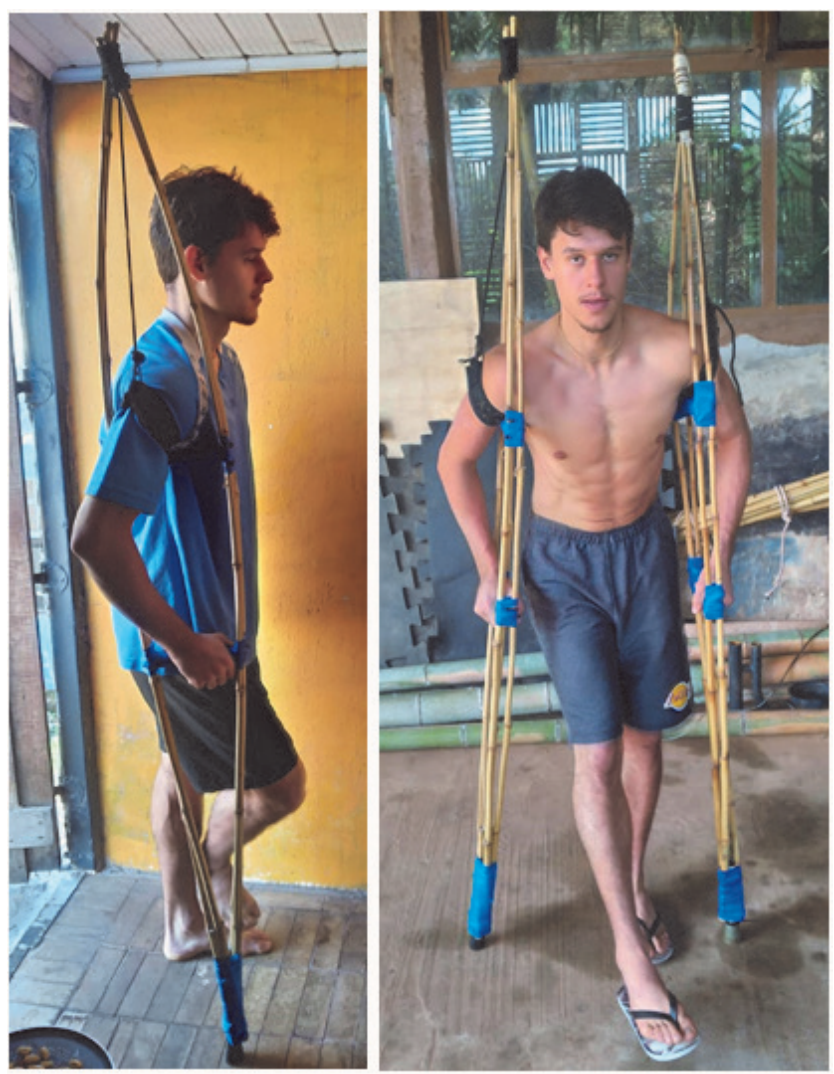

Figura 3 - Protótipo construído

Fonte: Autor 2020

\section{REFERÊNCIAS}

DINIZ, F. R. H. Muleta híbrida de baixo custo. 2017. F65. TCC - Curso de Engenharia Mecânica, Universidade Tecnológica Federal do Paraná. Pato Branco, 2017.

DONADUZZI, L. Projeto, montagem e simulação numérica de um auxiliador de locomoção para cães. TCC Curso de Eng. Mecânica. Universidade Tecnológica Federal do Paraná - UTFPR. Pato Branco, 2019.

OSTAPIV, F., OSTAPIV, G., CASTRO, G.C., STAHLSCHMIDT, J., "Computational simulation and vertical loading tests in bamboo geodesic domes". In: 25th International Congress of Mechanical Engineering ABCM, Uberlândia, MG, out. 2019. 